\title{
Effects of wording and stimulus format on the use of contingency information in causal judgment
}

\author{
PETER A. WHITE \\ Cardiff University, Cardiff, Wales
}

\begin{abstract}
There are four kinds of contingency information: occurrences and nonoccurrences of an effect in the presence and in the absence of a cause. Previous studies have shown that these four kinds are not given equal weight in causal judgment. The present research was designed to test two hypotheses about this unequal weighting: that weightings are influenced by the form of the question and other features of the stimulus materials and that unequal weightings occur, in part, because individual differences in the use of contingency information are not evenly distributed across the four kinds of information. Support was found for both hypotheses. However, the effects of question wording were not always as had been predicted, indicating that more needs to be learned about how people interpret the task, instructions, and materials they are given.
\end{abstract}

Often the causes of events are covert. A football team unexpectedly loses a match. A person develops an allergic reaction after eating a meal. A car collides with a lamppost. The local population of sparrowhawks crashes. Many things that matter greatly to us have causes that are not immediately obvious, and yet we wish to identify the cause or causes in order to understand, predict, control, intervene, or make use of our understanding in some way (Heider, 1958; White, 1984).

Where the mechanism is not apparent, there may still be cues and guides that help in the identification of causes. In the case of an allergic reaction, for example, the victim may note that the reaction tends to occur after some meals and not after others and that a certain ingredient tends to be present when the reaction occurs and is not present when the reaction does not occur. There is, therefore, a contingency between the ingredient and the reaction, and the victim may use this kind of information to judge that the ingredient is a cause of the reaction. Contingency information can be represented in a $2 \times 2$ table presenting information about the occurrence or nonoccurrence of a certain effect in the presence or absence of a candidate cause. The accepted conventions for identifying the cells of a $2 \times 2$ contingency table are shown in Table 1 .

Where a single candidate cause is considered in isolation, as in the Table 1 format, there is an objective description of the degree of contingency between that candidate and its effect. This is the $\Delta P$ rule (Jenkins \& Ward, 1965; McKenzie, 1994; Ward \& Jenkins, 1965), shown in Equation 1. Values of $\Delta P$ fall in the range -1 to +1 ,

Correspondence concerning this article should be addressed to P. A. White, School of Psychology, Candiff University, P. O. Box 901, Cardiff CF10 3YG, Wales (e-mail: whitepa@ cardiff.ac.uk). where +1 is perfect positive association and 0 is no association (zero correlation):

$$
\Delta P=A /(A+B)-C /(C+D) .
$$

Although causal judgments often conform closely to values of $\Delta P$ (Allan, 1993; Cheng, 1997; ValléeTourangeau, Hollingsworth, \& Murphy, 1998; Wasserman, Elek, Chatlosh, \& Baker, 1993), this is not always the case. In the $\Delta P$ rule, each of the four cells carries equal weight. However, several studies have found that the four cells are not weighted equally in causal judgment (Anderson \& Sheu, 1995; Kao \& Wasserman, 1993; Levin, Wasserman, \& Kao, 1993; Mandel \& Lehman, 1998; Wasserman, Dorner, \& Kao, 1990; Wasserman, Kao, Van Hamme, Katagiri, \& Young, 1996). These studies consistently found that the order of cell weights was $A>B>C>D$. This phenomenon is known as the cell weight inequality.

In the present research, two factors that may contribute to the cell weight inequality were investigated. One concerns the task set for participants-in particular, the wording of the causal question and the stimulus presentation format - and the other concerns the distribution of individual differences in cell use across the four cells.

Several studies have investigated the effect of the nature of the judgmental task on the use of contingency information. For example, there have been studies that have compared causal or predictive reasoning, where the cues are possible causes and the outcomes are effects, with diagnostic reasoning, where the cues are effects and the outcomes are possible causes (Matute, Arcediano, \& Miller, 1996; Waldmann, 2000, 2001). However, the possible effects of different forms of wording of the causal judgment task on the weightings of the four cells have not previously been investigated.

Every study of causal judgment must pose some causal question or ask participants to rate some causal statement. 
Table 1

Conventional Representation of Contingency Information

\begin{tabular}{ccc}
\hline & \multicolumn{2}{c}{ Effect Occurs } \\
\cline { 2 - 3 } Candidate Cause & Yes & No \\
\hline Present & A & B \\
Absent & C & D \\
\hline
\end{tabular}

Beyth-Marom (1982) and Crocker $(1981,1982)$ pointed out that the wording of this question and the surrounding instructions can influence the use of different kinds of contingency information and that the findings of causal judgment studies may be biased by wording effects. However, only Crocker (1982) conducted a study on this. Participants did not make causal judgments but indicated whether or not each kind of information was necessary and sufficient to make an accurate judgment. The cause was working out the day before a match or not, and the effect was the outcome of the match. The participants who were asked about a relationship between working out and winning showed a preference for Cell $\mathrm{A}$ and for causepresent information (Cells A and B) in general. The participants who were asked about a relationship between working out and losing showed the same preference for cause-present information but preferred Cell B to Cell A.

Studies of causal judgment often ask causal questions that implicitly point at cause-present, effect-present, or Cell A information. The studies that established the cell weight inequality all exemplify this. In Kao and Wasserman (1993), participants were asked to rate "the value of the fertilizer in promoting the Lanyu to bloom" (p. 1369). In Levin et al. (1993), participants were "asked to evaluate the effectiveness of the fertilizer on the plant's blooming" (p. 232). A similar form of words was used by Wasserman et al. (1996, p. 215). Anderson and Sheu (1995) used the question, "how likely the drug used... is the cause of side effects in patients" (p. 514). Wasserman et al. (1990) asked participants to "rate... the value of the drug for the treatment of psoriasis" (p. 514). Mandel and Lehman (1998) asked participants, "how would you characterize the effect of 'the input' on 'the output"' (p. 274), where "the input" and "the output" stood for various possible causes and effects.

In all these cases, only the positive value of the cause variable is explicit in the causal question, and in all except Wasserman et al. (1990) only the positive value of the effect variable is explicit. This may serve to focus participants' attention primarily on Cell A, where positive values of both are found, and secondarily on Cells B and C, where positive values of one or the other are found. Different but equally legitimate forms of wording may serve to focus attention in different ways, resulting in different patterns of cell use. The present research was designed to investigate this possibility.

The distribution of individual differences is also a possible explanationfor the cell weight inequality. Normatively, as shown in the $\Delta P$ rule, Cells $\mathrm{A}$ and $\mathrm{D}$ instances are confirmatory for the candidate being judged (i.e., they tend to increase $\Delta P$ ), and Cells $\mathrm{B}$ and $\mathrm{C}$ are disconfirmatory (they tend to decrease $\Delta P$ ). Judges do not always conform to these normative prescriptions, however. A study of the relation between reported and actual tendencies in cell use was conducted by White (2000). White (2000) found that many participants reported counternormative uses of some cells, and comparison with actual changes in judgment following instances of each kind revealed that these reports tended to be accurate. The relevant feature of this evidence is that counternormative tendencies were reported most commonly for Cells $\mathrm{C}$ and $\mathrm{D}$, and least often for Cells A and B, which somewhat resembles the ordering of cells in the cell weight inequality.

To see how the distribution of counternormative uses of the four cells can partly explain the cell weight inequality, it is necessary to distinguish between algebraic and absolute correlations. If participants make causal judgments about each of a series of problems and cell frequencies (the number of instances in a given cell) vary across problems, the correlation between an individual's judgments and cell frequencies across problems can be computed. These correlations can, of course, be positive or negative. The mean algebraic correlation is the mean of these correlations across individuals. To compute the mean absolute correlation, the signs are removed from the individual correlations; hence, mean absolute correlations range from 0 to 1 .

The evidence for the cell weight inequality is mostly based on mean algebraic correlations between judgments and cell frequencies. If some participants treat Cell D normatively and some counternormatively, the judgments of the former will tend to be positively correlated with Cell D frequency, and those of the latter will tend to be negatively correlated with it. The mean algebraic correlation will therefore tend to be close to zero, depending on the proportion of each kind of participant. It follows that, other things being equal, mean algebraic correlations should tend to vary with the proportion of participants who treat the type of information in question counternormatively. A better indication of the weight given to each cell can be derived from the mean absolute correlations. After all, a participant who treats Cell D information as disconfirmatory may give it as much weight as one who treats it as confirmatory; they differ only in the direction of the correlation.

If the distribution of counternormative tendencies in information use is a partial explanation for the cell weight inequality, we should find that the cell weight inequality is reduced, if not altogether eliminated, when weights are measured by absolute, rather than by algebraic, correlations. This hypothesis was tested in the present research.

The general strategy of all three experiments was to manipulate frequencies in the four cells orthogonally so that the contribution of each to causal judgment could be assessed and to manipulate features of question wording and stimulus presentation format to test the foregoing hypotheses as possible explanations for the cell weight inequality.

\section{EXPERIMENT 1}

Experiment 1 was designed as an orthogonal manipulation of frequencies in all four cells. In addition, as a 
between-subjects variable, the wording of the causal question was manipulated. A conventional form mentioning only the positive value of the cause variable was used for one group, and a contrasting form mentioning only the negative value of the cause variable was used for the other group. It was predicted that Cells $\mathrm{C}$ and $\mathrm{D}$ would carry greater weight than Cells $\mathrm{A}$ and $\mathrm{B}$ in the negative-wording group, because the causal question makes reference only to the absence of the cause.

\section{Method}

Participants.The participants were 63 first-year undergraduate students of psychology at Cardiff University, participating in return for course credit. Originally, 64 participated, but 1 was excluded prior to analysis for failing to comply with the instructions.

Stimulus materials. The stimulus materials consisted of a written questionnaire containing a page of instructions and 16 problems for judgment, each on a separate page. Initial written instructions to the participants in the positive-wording group asked them to imagine that they were a doctor investigating patients suffering from a disease that involved the appearance of blue spots on the skin. They were investigating the possible effects of a food additive identifed as Additive $\mathrm{X}$.

The instructions went on to describe the format of the information. Each page concerned a different patient. On each page, the patient's initials appeared at the top. Under this were three columns of information. The left column identified each of a series of meals eaten by the patient with a number. The middle column indicated whether each meal contained Additive $\mathrm{X}$ or not. The right column indicated whether the patient suffered from blue spots after eating the meal or not. Beneath this was the following question: "To what extent does Additive $\mathrm{X}$ cause an increase or decrease in the occurrence of blue spots in this patient after meals"?

The participants were instructed to answer this by writing a number from -100 to +100 beside it: -100 meant that Additive X causes a great decrease in the occurrence of blue spots in this patient after meals, +100 meant that Additive $\mathrm{X}$ causes a great increase in the occurrence of blue spots in this patient after meals, and 0 meant that Additive $\mathrm{X}$ has no effect on the occurrence of blue spots in this patient after meals. They could put any number between -100 and +100 , depending on how strongly Additive $\mathrm{X}$ caused an increase or a decrease in blue spots, in their judgment.

The instructions for the negative-wording group were identical, except that the expression "Additive X" was replaced throughout the instructions by the phrase "leaving Additive X out of the meal." This is the negative wording manipulation.

Following these instructions, causal judgment problems were presented, one to a page, each having the format described above. There were 16 problems altogether. The problems were randomly ordered, and a different random order was generated for each participant. Instances of information within problems were also randomly ordered.

Design. Positive versus negative wording was a between-subjects variable, with 31 participants in the positive-wording group and 32 in the negative-wording group. Frequency in each cell was manipulated as a within-subjects factor with two values, 4 and 8 . The number of instances per patient varied from 16 (all cell frequencies $=4$ ) to 32 (all cell frequencies $=8$ ). An example patient information sheet in given in Appendix A, which is for the problem with $a=$ $b=c=4$ and $d=8$.

Procedure.The participants were tested in groups of 2 or 3 in a large and comfortably furnished office. They were presented with the questionnaire and were told to ask questions if anything was not clear. None did so. Each participant then proceeded through the questionnaire under supervision at their own pace. When they had completed the questionnaire, they were thanked and given course credit.

\section{Results}

The analyses of most interest in these experiments are the effect size measures and the algebraic and absolute correlations reported below. A preliminary analysis of variance (ANOVA) serves two main purposes. It enables effects of the between-subjects variables to be assessed, and it also tests for significant main effects of cell frequency manipulations. The numerous interactions involved in a five-factor design are otherwise of lesser interest, particularly in view of the fact that some would be expected to be significant by chance alone. They are, therefore, described in Appendix B and will not be considered further here.

Initially, then, the data were analyzed with a $2 \times 2 \times 2$ $\times 2 \times 2$ mixed design ANOVA, with wording (positive vs. negative) as a between-subjects factor and Cell A frequency (4 vs. 8), Cell B frequency (4 vs. 8), Cell C frequency (4 vs. 8 ), and Cell D frequency (4 vs. 8 ) as within-subjects factors. Main effects of cell frequencies and interactions between cell frequencies and wording are described in two tables: $F$ ratios are presented in Table 2, and means are presented in Table 3.

Table 2 shows significant main effects for three of the four cells. Of more interest, however, are the significant interactions between wording and each of the four cells. The results of simple effects analyses for these interactions will be verbally summarized. For the positive-wording group, the results followed the usual pattern, with significantly higher means at higher cell frequencies for Cells A and D and at lower cell frequencies for Cells B and $\mathrm{C}$, as is shown in Table 3 (positive-wording column). For the negative-wording group, by contrast, there was a significantly higher mean at the higher cell frequency for Cell C and at the lower cell frequency for Cell D-in both cases, the opposite of the tendency for the positive-wording group. However, there was no significant difference for Cell A or for Cell B. The relevant means are shown in the negative-wording column of Table 3.

Cell weights were assessed using an effect size measure and algebraic and absolute correlations between judgments and cell frequencies. Effect sizes were estimated using the $R^{2}$ formula (Keppel, Saufley, \& Tokunaga, 1992), and these are reported in Table $4 .{ }^{1}$ For the positivewording group, the table shows the order $\mathrm{A}>\mathrm{B} \approx \mathrm{C}>$

Table 2

$F$ Ratios for Main Effects and Interactions Between Wording and Cell Frequencies: Experiment 1

\begin{tabular}{lrrc}
\hline \multicolumn{1}{c}{ Effect } & \multicolumn{1}{c}{$F$} & \multicolumn{1}{c}{$M S_{\mathrm{e}}$} & $p$ \\
\hline Wording & 9.41 & $1,559.26$ & $<.01$ \\
Cell A & 10.48 & 942.89 & $<.01$ \\
Cell B & 13.40 & 706.95 & $<.001$ \\
Cell C & 3.05 & $1,121.52$ & n.s. \\
Cell D & 8.74 & 680.53 & $<.01$ \\
Wording $\times$ Cell A & 24.88 & 942.89 & $<.001$ \\
Wording $\times$ Cell B & 13.62 & 706.95 & $<.001$ \\
Wording $\times$ Cell C & 61.92 & $1,121.52$ & $<.001$ \\
Wording $\times$ Cell D & 48.66 & 680.53 & $<.001$ \\
\hline
\end{tabular}

Note- $d f=1,61$ in all cases. 
Table 3

Mean Causal Judgments for Main Effects and Interactions With Wording: Experiment 1

\begin{tabular}{lcrrc}
\hline & & \multicolumn{3}{c}{ Wording } \\
\cline { 2 - 5 } Cell & Value & Positive & Negative & All \\
\hline A & 4 & -4.94 & -2.92 & -3.93 \\
A & 8 & +10.97 & -6.31 & +2.33 \\
B & 4 & +9.17 & -4.64 & +2.27 \\
B & 8 & -3.14 & -4.59 & -3.87 \\
C & 4 & +9.48 & -14.76 & -2.64 \\
C & 8 & -3.44 & +5.52 & +1.04 \\
D & 4 & -0.29 & +3.55 & +1.63 \\
D & 8 & +6.32 & -12.78 & -3.23 \\
All & & +3.01 & -4.61 & \\
\hline
\end{tabular}

D, with Cell D carrying only one third as much weight as Cell A. For the negative-wording group, effect sizes were substantial and similar for Cells $\mathrm{C}$ and $\mathrm{D}$ but were close to zero for Cells A and B.

Algebraic and absolute correlations between judgments and cell frequencies were computed for each participant, and the means are shown in Table 4. Correlations were compared across participants within wording groups, using a one-way ANOVA with repeated measures. Post hoc paired comparisons were carried out using the NewmanKeuls test.

Considering algebraic correlations first, in the positivewording group, the means for Cells A and D were positive, and those for Cells B and C were negative. Significant differences between the weights of each cell can properly be assessed only if the signs of the individual participants' correlations are reversed for Cells B and C, so that the direction of the deviation from zero is the same for all four cells. This was done prior to analysis. For the positivewording group $\left[F(3,90)=5.32, M S_{\mathrm{e}}=0.06, p<.01\right]$. Post hoc comparisons revealed a lower mean for Cell D than for the other three cells, which did not differ significantly. In the negative-wording group, the means for Cells $A$ and $D$ were negative, so the same procedure was applied to these two cells prior to analysis $[F(3,93)=17.21$, $\left.M S_{\mathrm{e}}=0.06, p<.001\right]$. Post hoc comparisons revealed significantly higher means for Cells $\mathrm{C}$ and $\mathrm{D}$ than for Cells A and B.

For absolute correlations in the positive-wording group $F(3,90)=2.19, M S_{\mathrm{e}}=0.04$, n.s. For absolute correlations in the negative-wording group $F(3,93)=6.87, M S_{\mathrm{e}}=$ $0.03, p<.001$. Post hoc comparisons revealed a significantly higher mean for Cell C than for Cells A and B and no other differences.
In the positive wording group, the mean absolute correlation was significantly higher than the mean algebraic correlation for Cell D [ $t(30)=3.24, p<.01]$, but not for the other three cells. In the negative-wording group, the mean absolute correlation was significantly higher than the mean algebraic correlation for Cell A $[t(31)=3.88$, $p<.001]$ and for Cell B $[t(31)=3.95, p<.001]$, but not for Cells C and D.

\section{Discussion}

The results show contrasting patterns of cell use in the two groups. In the positive-wording group, the usual cell weight inequality was obtained, except that there was no significant difference between the contributions of Cells $\mathrm{B}$ and $\mathrm{C}$ to causal judgment. In the negative-wording group, however, Cells C and D were given substantially more weight than Cells A and B, for which weights were close to zero.

One possible interpretation of this is that the effect of the negative wording is to transform the positive and negative import of the four cells. In other words, with a negatively worded causal question, a Cell C instance counts as a positive instance for that question, and a Cell A instance counts as a negative instance. Under this view, the participants still exhibited a kind of positivity bias, and the effect was to reverse the usual pattern of cell weights because the negative wording of the question reverses the positive and the negative values of the four cells.

This is entirely possible, but the results do not show an exact reversal of the cell weight inequality. Judgment was based almost entirely on Cells $\mathrm{C}$ and $\mathrm{D}$, and there was no significant tendency to use either of the other cells. In the positive-wording group (as in other, similar studies), Cell A was given more weight than Cell $\mathrm{B}$, but in the negative-wording group, there was no tendency for Cell C to be given more weight than Cell D, which would be expected if the participants had simply reversed the valuations of the cells. In the positive-wording group (as in similar studies), Cell C was given more weight than Cell D, but in the negative-wording group, there was no tendency for Cell A to be given more weight than Cell B. The negative wording has, therefore, resulted in a more extensive reevaluation of the four cells than a simple reversal of valuations would imply.

Comparisons between mean algebraic and absolute correlations between causal judgments and cell frequencies supported the hypothesis that the cell weight inequality is partly attributable to the distribution of individual differences in cell use across the four cells. In both groups, mean

Table 4

Effect Sizes and Mean Correlations Between Cell Frequencies and Causal Judgments: Experiment 1

\begin{tabular}{|c|c|c|c|c|c|c|c|c|}
\hline \multirow[b]{2}{*}{ Measure } & \multicolumn{4}{|c|}{ Positive Wording } & \multicolumn{4}{|c|}{ Negative Wording } \\
\hline & A & B & $\mathrm{C}$ & $\mathrm{D}$ & A & B & $\mathrm{C}$ & $\mathrm{D}$ \\
\hline Effect size & .72 & .53 & .51 & .23 & .03 & .00 & .52 & .59 \\
\hline Algebraic correlation & +.38 & -.27 & -.30 & +.14 & -.03 & +.02 & +.35 & -.31 \\
\hline Absolute correlation & .38 & .30 & .31 & .25 & .26 & .22 & .42 & .33 \\
\hline
\end{tabular}


absolute correlations showed less variation than mean algebraic correlations did. In the negative-wording group, therefore, the participants did not entirely neglect Cells A and $\mathrm{B}$; rather, the proportion treating Cell $\mathrm{A}$ as confirmatory was matched by the proportion treating Cell A as disconfirmatory, and the same was true for Cell B. In the positive-wording group, there were no significant differences between mean absolute correlations. This indicates that the lesser weight apparently given to Cell $\mathrm{D}$, as evidenced by the effect size and algebraic correlation measures, is partly attributable to individual differences in the use of Cell D, not to a tendency to neglect that kind of information.

\section{EXPERIMENT 2}

The wording used in the positive-wording group resembles that used in most published studies of causal judgment (see the causal questions quoted in the introduction) in that the cause is placed first: The participant is asked to judge what the causal candidate does. This will be called the active wording. This form of wording may encourage participants to look at instances in which the causal candidate is present to see how often the effect occurs, thereby increasing the weight given to Cells A and B. The order of things in the causal question can be reversed: Instead of asking to what extent the causal candidate causes the effect, one could ask to what extent the effect is caused by the causal candidate. This will be called the passive wording. Placing the effect first in the question, instead of the cause, may encourage participants to look at instances of the effect to see how often the cause is present, thereby increasing the weight given to Cells A and C. Under this reasoning, therefore, Cell $\mathrm{B}$ should carry less weight with the passive wording than with the active wording, and the opposite should be the case for Cell C. Experiment 2 was designed to test this hypothesis.

In addition, the use of different cells may depend on what participants assume about other possible causes of the effect. If the effect sometimes occurs when the cause being judged is absent (Cell C instances), that implies that there is at least one other thing that can cause it as well. But do people assume that other possible causes could be present when the candidate being judged is present or that they could not? For someone who assumes that other possible causes are not present when the candidate cause is present, Cells A and B give relatively unambiguousinformation: Since the candidate cause is the only possible cause of the effect, the rate of occurrence of the effect is a good guide to the extent to which the candidate causes the effect. Such a person would therefore give much weight to Cells A and B and little or none to Cells C and D. For someone who assumes that other possible causes could be present when the candidate is present, all four cells carry an equal degree of ambiguity, in the absence of information about these other possible causes. Such a person would therefore give more nearly equal weight to all four cells.

Experiment 2 was designed to investigate this by manipulating information about the presence and absence of other possible causes in a between-subjects design. One group of participants was instructed that there was no information about whether other possible causes of the effect were present or absent. This is the other causes possible group. Another group was informed that, when the candidate cause was present, all other possible causes had been ruled out but that, when the candidate cause was absent, there was no information about whether other possible causes of the effect were present or absent. The latter stipulation was necessary because there is no other way to account for Cell C instances. This is the other causes not possible group.

\section{Method}

Participants. The participants were 80 first-year undergraduate students of psychology at Cardiff University, participating in return for course credit.

Stimulus materials. The stimulus materials consisted of a written questionnaire containing a page of instructions and 16 problems for judgment, each on a separate page. Initial written instructions to the participants in the active-wording, other causes possible group began in a similar way to those of Experiment 1, except that the name of the food additive was changed to W97. The next paragraph read as follows.

There are several substances that might cause the allergic reactions and you are testing one of them, a food additive called W97. When several substances could be causing the reactions, you have to try to tell them apart. That means manipulating the presence and absence of W97 in a series of meals. In each meal, you know whether W97 is present or absent, but you don't know whether any of the other substances that might cause the allergic reactions are present or absent. So if an allergic reaction occurs after a meal with W97 present it could be caused either by W97 or by one of the other substances (because you don't know if any of the others were present or not). But if an allergic reaction occurs after a meal with W97 absent, it could only be caused by one of the other substances.

For each patient you will see the following question at the bottom of the page:

"To what extent did W97 cause allergic reactions in this patient?"

To answer this question write a number from 0 (zero) to 100 beside the statement. 0 (zero) means that W97 did not cause allergic reactions in this patient at all, and 100 means that W97 was a very strong cause of allergic reactions in this patient. The more you think W97 caused allergic reactions in this patient, the higher the number you should put.

For the participants in the other causes not possible group, the instructions were the same, except that the italicized passage in the instructions above was replaced by the following.

In each meal, you know whether W97 is present or absent. You also know that when W97 is present, all of the other possible causes of the allergic reactions are absent, because you have designed the study so as to rule them out. When W97 is absent you don't know whether any of the other substances that might cause the allergic reactions are present or absent. So if an allergic reaction occurs after a meal with W97 present it could only be caused by W97 (because you know that none of the others was present)

For the participants in the passive-wording group, the causal question read, "To what extent were this patient's allergic reactions caused by W97'?

Following these instructions, the 16 causal judgment problems were presented with the same format as that in Experiment 1.

Design. Other-causes information was a between-subjects variable with two levels, possible and not possible. Causal question was a between-subjects variable with two levels, active wording and passive wording. Frequencies in each cell were manipulated as withinsubjects factors. Frequencies in Cells A and D were 6 or 12, and fre- 
Table 5

Main Effect $\boldsymbol{F}$ Ratios and Mean Causal Judgments: Experiment 2

\begin{tabular}{lrrrcccc}
\hline & & & & & \multicolumn{2}{c}{ Mean } \\
\cline { 6 - 7 } Wording & Effect & $F$ Ratio & \multicolumn{1}{c}{$M S_{\mathrm{e}}$} & $p$ & Low & High \\
\hline Active & Cell A & 95.10 & 280.52 & $<.001$ & 41.53 & 54.45 \\
& Cell B & 51.23 & 328.94 & $<.001$ & 53.12 & 42.86 \\
& Cell C & 17.52 & 427.84 & $<.001$ & 51.41 & 44.57 \\
& Cell D & 3.68 & $2,722.50$ & n.s. & 46.89 & 49.09 \\
Passive & Cell A & 100.75 & 204.35 & $<.001$ & 41.89 & 53.23 \\
& Cell B & 18.20 & 346.93 & $<.001$ & 50.70 & 44.42 \\
& Cell C & 15.00 & 473.62 & $<.001$ & 50.89 & 44.23 \\
& Cell D & 14.48 & 390.37 & $<.001$ & 44.59 & 50.53 \\
\hline
\end{tabular}

Note- $d f=1,38$ for all $F$ ratios. "Low" and "High" stand for low and high values of cell frequencies.

quencies in Cells B and $\mathrm{C}$ were 3 or 6 . The total number of instances per problem therefore varied from 18 to 36 .

Procedure. All details of the procedure were the same as those in Experiment 1.

\section{Results}

Data were analyzed with a $2 \times 2 \times 2 \times 2 \times 2 \times 2$ mixed design ANOVA, with other-causes information (possible vs. not possible) and causal question (active wording vs. passive wording) as between-subjects factors and Cell A frequency (6 vs. 12), Cell B frequency (3 vs. 6), Cell C frequency ( 3 vs. 6 ), and Cell D frequency (6 vs. 12 ) as within-subjects factors. The results relating to the between-subjects variables are considered first.

Other-causes information. There was a significant main effect of other-causes information $[F(1,76)=7.34$, $\left.M S_{\mathrm{e}}=4,109.23, p<.01\right]$, with a higher mean in the notpossible group (52.63) than in the possible group (42.92). There was also a significant three-way interaction between other-causes information, causal question, and Cell D frequency $\left[F(1,76)=7.18, M S_{\mathrm{e}}=299.77, p<.01\right]$. Post hoc paired comparisons with the Newman-Keuls test revealed that the main effect of Cell D was present at all combinations of other-causes information and causal question, except the combination of other causes possible and active wording, where there was a nonsignificant reversal of the trend. There were no other significant results involving other-causes information.

Causal question. There was no significant main effect of causal question $\left[F(1,76)=0.01, M S_{\mathrm{e}}=4,109.23\right]$. However, this factor did enter into several significant or marginally significant interactions. These included a marginally significantinteraction with Cell $\mathrm{B}$ frequency $[F(1,76)=$ $\left.3.75, M S_{\mathrm{e}}=337.93, p=.056\right]$, a marginally significant interaction with Cell $\mathrm{D}$ frequency $\left[F(1,76)=3.75, M S_{\mathrm{e}}=\right.$ $299.77, p=.056]$, a significant four-way interaction with Cells A, B, and C $\left[F(1,76)=4.78, M S_{\mathrm{e}}=156.41, p<.05\right]$, and a marginally significant four-way interaction with Cells A, B, and D $\left[F(1,76)=3.53, M S_{\mathrm{e}}=221.29, p=\right.$ $.064]$, as well as the aforementioned three-way interaction with other-causes information and Cell D frequency.

The 2 two-way interactions are of most interest. The interaction with Cell B shows a reduced effect of Cell B in the passive-wording group. The interaction with Cell D shows an increased effect of Cell $\mathrm{D}$ in the passive-wording group. In fact, separate five-way ANOVAs on the active and passive groups yielded a significant effect of Cell D only in the passive-wording group. $F$ ratios for main effects of cell frequencies from these analyses are reported in Table 5. In the five significant interactions described in Appendix B, there was no violation of the directions of difference in the significant main effects: The differences that made the interactions significant appear to be ones of degree rather than kind.

Cell weights and correlations. The main interest lies in the evidence of different cell weighting in the activeand passive-wording groups. This was assessed, as in Experiment 1 , by both effect sizes and mean correlations with cell frequencies. The results are presented in Table 6 . Effect sizes show the usual $\mathrm{A}>\mathrm{B}>\mathrm{C}>\mathrm{D}$ ordering in the active group. In the passive group, Cell A carried more weight than the other three, but the differences between the other three are probably too small to be meaningful. Comparison between the active and the passive groups on the effect size measure shows that Cell B carried more weight in the active group than in the passive group and Cell D carried more weight in the passive group than in the active group.

For algebraic correlations the means for Cells B and C were negative. Therefore, to facilitate assessment of the relative weights of each cell, the signs of individual participants' correlations were reversed, as in Experiment 1. The resultant data were analyzed with a $2 \times 4$ mixed design ANOVA, with wording (active vs. passive) as betweensubjects factor and cells (A vs. B vs. C vs. D) as a withinsubjects factor. There was a significant main effect of cells $\left[F(3,234)=17.17, M S_{\mathrm{e}}=0.07, p<.001\right]$. Post hoc paired comparisons with the Newman-Keuls test revealed the order $\mathrm{A}>\mathrm{B} \approx \mathrm{C}>\mathrm{D}$. There was a significant interaction $\left[F(3,234)=3.01, M S_{\mathrm{e}}=0.07, p<.05\right]$. Simple effects analysis revealed a significant effect of wording for

Table 6

Effect Sizes and Mean Correlations Between Cell Frequencies and Causal Judgments: Experiment 2

\begin{tabular}{lrrrrrrrrr}
\hline & \multicolumn{4}{c}{ Active Wording } & & \multicolumn{5}{c}{ Passive Wording } \\
\cline { 2 - 4 } \cline { 8 - 10 } \multicolumn{1}{c}{ Result } & \multicolumn{1}{c}{$\mathrm{A}$} & $\mathrm{B}$ & $\mathrm{C}$ & $\mathrm{D}$ & & $\mathrm{A}$ & $\mathrm{B}$ & $\mathrm{C}$ & $\mathrm{D}$ \\
\hline Effect size & .71 & .57 & .32 & .09 & & .73 & .32 & .28 & .28 \\
Algebraic correlation & +.42 & -.30 & -.18 & +.05 & & .37 & -.17 & -.22 & +.16 \\
Absolute correlation & .44 & .31 & .28 & .20 & & .38 & .23 & .31 & .27 \\
\hline
\end{tabular}


Cell B $\left[F(1,78)=6.39, M S_{\mathrm{e}}=0.05, p<.05\right]$ and a marginally significant effect for Cell $\mathrm{D}[F(1,78)=3.39$, $\left.M S_{\mathrm{e}}=0.07, p=.07\right]$. There was no significant difference for Cell A or for Cell C ( $F<1$ in both cases). There was a significant effect of cells in the active-wording group $\left[F(3,234)=14.48, M S_{\mathrm{e}}=0.07, p<.001\right]$, with post hoc comparisons revealing the order $\mathrm{A}>\mathrm{B}>\mathrm{C}>\mathrm{D}$. There was a significant effect of cells in the passive-wording $\operatorname{group}\left[F(3,234)=5.71, M S_{\mathrm{e}}=0.05, p<.001\right]$. Post hoc comparisons revealed significant differences between Cell A and the other three cells, which did not differ significantly. The means are presented in Table 6 .

Absolute correlations were analyzed with a $2 \times 4$ mixed design ANOVA, with wording (active vs. passive) as a between-subjects factor and cells (A vs. B vs. C vs. D) as a within-subjects factor. There was a significant effect of cells $\left[F(3,234)=12.61, M S_{\mathrm{e}}=0.04, p<.001\right]$. Post hoc comparisons revealed a significantly higher mean for Cell A than for the other three cells, which did not differ significantly. There was a marginally significant interaction $\left[F(3,234)=2.49, M S_{\mathrm{e}}=0.04, p=.06\right]$. Simple effects analysis revealed a marginally significant effect of wording for Cell B $\left[F(1,78)=3.20, M S_{\mathrm{e}}=0.03, p=.08\right]$ and for Cell $\mathrm{D}\left[F(1,78)=3.32, M S_{\mathrm{e}}=0.03, p=.07\right]$. There was no significant effect for Cell $\mathrm{A}[F(1,78)=1.50$, $\left.M S_{\mathrm{e}}=0.04\right]$ or for Cell C $\left[F(1,78)<1, M S_{\mathrm{e}}=0.03\right]$. There was a significant effect of cells in the active-wording group $\left[F(3,234)=10.58, M S_{\mathrm{e}}=0.04, p<.001\right]$. Post hoc comparisons revealed a significantly higher mean for Cell A than for the other three cells and a significantly higher mean for Cell B than for Cell D. There was a significant effect of cells in the passive-wording group $\left[F(3,234)=4.52, M S_{\mathrm{e}}=0.04, p<.01\right]$. Post hoc comparisons revealed a significantly higher mean for Cell A than for Cells B and D and no other significant differences. The means are presented in Table 6 .

In the active-wording group, the mean absolute correlation was significantly higher than the mean algebraic correlation for Cell C $[t(39)=2.90, p<.01]$ and for Cell D $[t(39)=3.50, p<.01]$, but not for Cells A and B. In the passive-wording group, the mean absolute correlation was significantly higher than the mean algebraic correlation for Cell B $[t(39)=2.93]$, Cell C $[t(39)=2.91]$, and Cell $\mathrm{D}[t(39)=3.44 ; p<.01$ in all cases], but not for Cell A.

\section{Discussion}

The results showed significant effects of both betweensubjects variables, but not exactly as predicted. Manipulating information about the possibility of other causes in the presence of the causal candidate was predicted to affect the cell weight inequality. Specifically, greater reliance on Cells A and B was predicted when there were no other possible causes in the presence of the candidate. However, the main result for this factor was a general tendency for lower ratings when there was a possibility of other causes being present. The most likely interpretation of this result is that the explicit possibility of other causes in the presence of the candidate increased the participants' uncertainty about the extent to which the candidate caused the effect, rather than specifically apportioning uncertainty among the four cells.

It was predicted that passive wording would result in greater weight being given to Cell C and less to Cell $\mathrm{B}$. The results supported the latter prediction: The effect size for Cell B in the passive group was only half what it was in the active group, and the mean algebraic correlation was significantly lower in the passive-wording group than in the active-wording group. However, there was no discernible effect of wording on the use of Cell C information. Instead, there was a substantial increase in weight given to Cell D information: The effect size for Cell D in the passive group was three times greater than that in the active group, and the mean algebraic correlation was marginally significantly higher in the passive-wording group than in the active-wording group.

Absolute mean correlations yielded further support for the hypothesis that the cell weight inequality is partly explained by the distribution of counternormative uses of information. Mean absolute correlations showed less variation and fewer significant differences than did mean algebraic correlations in both causal question groups (Table 6).

\section{EXPERIMENT 3}

Experiments 1 and 2 both yielded a similar pattern in respect to the difference between mean algebraic and absolute correlations. With the exception of the negativewording group in Experiment 1, the mean absolute correlation for Cell D was significantly more different from zero than was the mean algebraic correlation. The same was found for Cells B and C in one or two cases, but not in all. This means that, particularly in the case of Cell D, individuals differ in the kind of use they make of Cell D information, some treating it as confirmatory and some as disconfirmatory. This is consistent with the findings of White (2000) on the distribution of individual differences in cell use across cells.

One possible explanation for this is that individuals are uncertain as to what use to make of Cell D information in causal judgment and perhaps, to a lesser extent, Cells B and $\mathrm{C}$ as well. This is not altogether surprising. Borrowing an example from Nisbett and Ross (1980), consider how one would assess whether God answers prayers or not. It is easy to see the relevance of things prayed for and got (Cell A) and even of things prayed for and not got (Cell B). It is perhaps less easy to see the relevance of things that were got but not prayed for (Cell C) because if something is not prayed for, there is no opportunity for God to answer or not answer the prayer. But as Nisbett and Ross pointed out, the relevance of things that were not prayed for and not got is hard to comprehend. I have never prayed for the chance to visit the planet Neptune, and indeed, that chance has never come my way, but how does knowing that help me to decide whether God answers prayers or not? In experiments or controlled observations in which the content of Cell D is set by the way in which 
Table 7

Significant $F$ Ratios and Mean Causal Judgments: Experiment 3

\begin{tabular}{lccccc}
\hline & & & & \multicolumn{2}{c}{ Mean } \\
\cline { 5 - 6 } Effect & $F$ Ratio & $M S_{\mathrm{e}}$ & $p$ & Low & High \\
\hline Cell A & 377.99 & 593.01 & $<.001$ & +18.47 & +56.87 \\
Cell B & 149.16 & 634.57 & $<.001$ & +50.15 & +25.19 \\
Cell C & 146.43 & 543.50 & $<.001$ & +49.11 & +26.23 \\
Cell D & 47.35 & 994.11 & $<.001$ & +28.27 & +46.47 \\
\hline
\end{tabular}

Note- $d f=1,37$ for all $F$ ratios. "Low" and "High" stand for low and high values of cell frequencies.

the observations are made, the role of Cell D in causal inference is clear. But in everyday life, where the set of instances that could fall into Cell D has no obvious limit, its relevance to causal judgment is less clear, and actually compiling instances in any systematic way is not feasible.

In the present experiments, as in most causal judgment experiments, Cell D instances were supplied for the participant, but no guidance was given on how these instances are supposed to be used. People may, therefore, approach the causal judgment problem with an attitude of mind appropriate to causal judgment in the context of everyday life, where the relevance and feasibility of using Cell D instances in causal inference is either unclear or low. In the experimental context, therefore, different individuals make different decisions about how to use it, and nonsignificant or weak effects result from that.

If this is the case, one way to increase consistent utilization of Cell D information is to provide a context that clarifies the function of Cell D information in causal judgment. Experiment 3 was designed to test this hypothesis. Specifically, cause-present information (Cells A and B) and cause-absent information (Cells $\mathrm{C}$ and $\mathrm{D}$ ) are separated in presentation, and cause-absent information is given the explicit function of providing a baseline against which cause-present information is to be assessed. If people comprehend the baseline function of cause-absent information, they should make greater use of this information in their causal judgments.

\section{Method}

Participants. The participants were 38 first-year undergraduate students of psychology at Cardiff University, participating in return for course credit.

Stimulus materials. The stimulus materials consisted of a written questionnaire containing a page of instructions and 16 problems for judgment, each on a separate page. Initial written instructions informed the participants that marine biologists were interested in a fish called the polychrome parrotfish, of which there were many species. They were investigating the possibility that a trace mineral (MS) sometimes found in seawater affected the occurrence of green spots on these fish. The instructions continued as follows:

The basic method is to set up aquaria so that fish lay eggs in water that has MS added to it, and then to see how many of the offspring have green spots when they grow up. However before they can do that they have to get an idea of how often fish of that species have green spots when there was no MS in the seawater when the eggs were laid, to see what difference MS makes. Of course this too can vary from one species of parrotfish to another, so this measurement has to be made separately for each species.
On the following pages you will see information about tests carried out on different species of parrotfish. There is one species on each page and the top of the page identifies the species with a code number. Under that you will see two sets of information: the baseline information, which is a group of fish hatched from eggs laid in water that had no MS in it, and the experimental information, which is a group of fish hatched from eggs laid in water that did have MS in it. In each case there will be two columns of information. The first column just identif ies each individual fish with a number, and the second column tells you whether the fish had green spots or not.

This information explicated the baseline function of the causeabsent information and separated cause-absent and cause-present information in the stimulus presentation.

At the bottom of each page was the following question: "How does MS affect the occurrence of green spots in this species of parrotfish?" Instructions for answering this question were similar to those used in Experiment 1, with changes in wording appropriate to the scenario content.

Following these instructions, causal judgment problems were presented, one to a page. Each problem had the same format. At the top of the page appeared the number of the species (randomly chosen from 01 to 99). Beneath this was a heading reading "Baseline information (eggs laid in water with no MS in it)." Beneath this were two columns of information. One column identified each fish with a number, and the other column indicated whether the fish had green spots (yes or no). Beneath these was a heading reading "Experimental information (eggs laid in water with MS in it)." Beneath this were two columns, as in the baseline information. Beneath these was the question, "How does MS affect the occurrence of green spots in this species of parrotfish"?

There were 16 problems altogether. The problems were randomly ordered, and a different random order was generated for each participant. Instances of information within each heading in each problem were also randomly ordered.

Design and Procedure. There were four within-subjects variables, an orthogonal manipulation of cell frequencies. In this experiment, frequencies in Cells A and D were 4 and 12, and frequencies in Cells B and C were 2 and 6 . All details of the procedure were the same as those in Experiment 1. The total number of instances per problem therefore varied from 12 to 36 .

\section{Results}

Data were analyzed with a 2 (Cell A frequency, 4 vs. 12) $\times 2$ (Cell B frequency, 2 vs. 6$) \times 2$ Cell C frequency $(2$ vs. 6$) \times 2$ Cell $D$ frequency (4 vs. 12 ) within-subjects ANOVA. Main effect $F$ ratios are reported in Table 7. In the three significant interactions described in Appendix B, the directions of the respective main effects were preserved throughout.

Effect sizes and mean correlations are reported in Table 8. Effect sizes were in all cases higher than those in the previous experiments. However, the increase in effect size was greatest for Cell D, with Cells B and C showing intermediate increases and Cell A the least. Equal weighting of the four cells has not been achieved, but these results

Table 8

Effect Sizes and Mean Correlations Between Cell Frequencies and Causal Judgments: Experiment 3

\begin{tabular}{lrrrr}
\hline \multirow{2}{*}{\multicolumn{1}{c}{ Result }} & \multicolumn{5}{c}{ Cell } \\
\cline { 2 - 5 } & $\mathrm{A}$ & $\mathrm{B}$ & \multicolumn{1}{c}{$\mathrm{C}$} & \multicolumn{1}{c}{$\mathrm{D}$} \\
\hline Effect size & .91 & .80 & .80 & .56 \\
Algebraic correlation & +.56 & -.37 & -.34 & +.27 \\
Absolute correlation & .56 & .39 & .35 & .30 \\
\hline
\end{tabular}


Table 9

Proportions of Participants With

Counternormative Correlations Between

Judgment and Cell Frequency, All Experiments

\begin{tabular}{clllll}
\hline & & \multicolumn{4}{c}{ Cell } \\
\cline { 3 - 6 } Experiment & \multicolumn{1}{c}{ Group } & $\mathrm{A}$ & $\mathrm{B}$ & $\mathrm{C}$ & $\mathrm{D}$ \\
\hline 1 & positive wording & .00 & .13 & .06 & .39 \\
2 & active wording & .02 & .02 & .22 & .32 \\
& passive wording & .05 & .22 & .22 & .32 \\
3 & & .00 & .03 & .03 & .11 \\
\hline
\end{tabular}

show a closer approach to equal weighting than has previously been obtained.

For algebraic correlations, the means for Cells B and C were negative. As in the previous experiments, therefore, the signs of individual correlations for these cells were reversed to permit assessment of relative weights. The resultant data were analyzed with a one-way ANOVA with repeated measures $\left[F(3,111)=20.93, M S_{\mathrm{e}}=0.03, p<\right.$ .001]. Post hoc comparisons revealed the order $\mathrm{A}>\mathrm{B} \approx$ $\mathrm{C}>\mathrm{D}$. For absolute correlations, $F(3,111)=19.64$, $M S_{\mathrm{e}}=0.02, p<.001$. Post hoc comparisons revealed a significantly higher mean for Cell A than for the other three cells and a significantly higher mean for Cell B than for Cell D. Despite these significant differences, the mean algebraic correlation for Cell D was substantially higher than in the previous experiments, and the means for the other three cells showed moderate increases.

There was greater consistency between participants in the use of the four cells in this experiment. This is shown by a count of the proportions of participants showing counternormative correlations between judgments and cell frequencies for each cell in each experiment. These are depicted in Table 9; the negative-wording condition of Experiment 1 is omitted. This table shows almost uniformly low proportions of participants with counternormative correlations in Experiment 3. The proportion of .11 for Cell D equals 4 participants, so although it is probably no accident that the proportion was highest for Cell D, the difference from each of the other cells would not be statistically significant. For each cell, proportions of participants with counternormative correlations were compared across experiments, using the $\chi^{2}$ test. For Cell A, proportions were uniformly low, and there were no significant differences. For Cell B, the proportion in Experiment 3 was significantly lower than that in the passive-wording condition of Experiment $2\left[\chi^{2}(1)=6.88, p<.05\right]$. For Cell C, the proportion in Experiment 3 was significantly lower than those in the active- and passive-wording conditions of Experiment 2 [in both cases, $\chi^{2}(1)=6.88, p<.05$ ] For Cell D, the proportion in Experiment 3 was significantly lower in all three comparisons. For the comparison with the positive-wording condition of Experiment 1, $\chi^{2}(1)=7.61$, $p<.05$, and for the active- and passive-wording conditions of Experiment 2, in both cases $\chi^{2}(1)=5.52, p<.05$.

\section{Discussion}

The alteration to presentation format and instructions in this experiment did not produce equal weighting of all four cells. However, cell weights were more nearly equal than in any previous experiment, and the weight accorded to Cell $\mathrm{D}$ in particular was substantially greater than any seen before. A general increase in cell weights could be explained by the greater size of the manipulation of cell frequencies, which resulted in a range of objective contingencies approximately $50 \%$ greater than in the previous experiments. However, the increase in effect size and correlations for Cell D was approximately $430 \%$ and disproportionate to that for the other three cells, so it cannot wholly be explained in this way. There was also a higher level of consistency between the participants in their use of contingency information, particularly in the case of Cell D, where the proportion of participants with counternormative correlations between judgment and cell frequencies was considerably lower than in previous experiments. These results support the hypothesis that providing a context that makes the function of cause-absent information clear leads to more consistent and normative use of that information.

\section{GENERAL DISCUSSION}

These experiments were designed to investigate effects of question wording, instructions, and stimulus presentation format on causal judgment from contingency information. Causal questions in published experiments usually explicitly mention only the positive value of the cause and effect variables, so Experiment 1 compared this wording with a wording that explicitly mentioned only the negative value of the cause variable. The results showed not just a reversal of the usual $\mathrm{A}>\mathrm{B}>\mathrm{C}>\mathrm{D}$ ordering, but also almost complete neglect of Cells A and B and roughly equal weight given to Cells $\mathrm{C}$ and D. Experiment 2 compared the standard wording using the active voice ("causes") with wording using the passive voice ("caused by"). This resulted in a tendency to give less weight to Cell B and more to Cell D. Experiment 3 altered the presentation format, separating cause-present from cause-absent information and giving instructions that established a function for the cause-absent information. This led to more nearly equal use of the four cells and greater conformity to normative notions of cell value.

In addition, in the first two experiments, mean absolute correlations showed less difference between the four cells than mean algebraic correlations did. These results supported the hypothesis that the cell weight inequality is partly attributable to the distribution of individual differences in cell use across the four cells. Counternormative or other idiosyncratic uses of information tend to be more common for Cells C and D than for Cells A and B (White, 2000), and this tends to reduce algebraic, but not absolute, correlations.

There were several significanteffects of question wording and format on the use of the four cells for making causal judgments. However, the results were not always as predicted, and no manipulation resulted in equal weighting of all four cells. These results have implications for the study of causal judgment. The usual form of wording, in which 
only positive values of cause and effect are mentioned, is not a neutral form of words and does not reveal the true use of the four types of contingency information any more than any other form of words does. The effects of changing the wording of the causal question may not be profound, but they are significant and, therefore, justify questioning whether all of the results of causal judgment studies would generalize to all reasonable forms of wording.

Furthermore, the difficulty of predicting the effects of manipulating question wording indicates that the meanings participants attach to forms of words (and this includes instructions as well as the causal question) are perhaps subtly different from the meanings attached to them by professional scientists. Scientists understand principles of orthogonal manipulation, control groups, equal weighting of different kinds of information, and the function of baseline information. Untrained laypeople cannot be assumed to share this understanding. Instead, they possess an understanding that is geared to the problems of causal inference in the relatively poorly controlled conditions of everyday life, where the range of instances that could contribute to Cells C and D is not well defined. Confronted with a set of observations that range over all four cells of the contingency table, they may attach either no meaning to some kinds of information or meanings that are modified by the wording of the causal question in ways that are different from what a scientist might expect. The significant results obtained in these experiments may provide clues to the kinds of meaning people attribute to the causal questions they are asked and the kinds of information they must use to answer them.

On the other hand, the results of Experiment 3 demonstrated that high levels of consistency and conformity to normative prescriptions can be obtained in causal judgment experiments if cause-absent information, particularly Cell D information, is given an explicit function in the causal judgment task. The cell weight inequality was not abolished in that experiment, but the greater weight given particularly to Cell D indicates that the cell weight inequality is partly explained by the use of a stimulus presentation format in which the functions of the different types of information are not explicated or differentiated. Again, this is not a neutral presentation format. It is one of a number of possible ways of presenting contingency information, and there is no a priori reason to assume that it reveals how people truly use contingency information more than any other possible format does.

Other hypotheses have been proposed for the cell weight inequality. Levin et al. (1993) proposed that the effect arose from a positive instance-testing bias, focusing attention more on cells with positive values of cause or effect. Mandel and Lehman (1998) further proposed a preference for sufficiency information (whether the effect fails to occur when the cause is present) over necessity information (whether the effect occurs when the cause is absent) as an explanation for the greater weight given to Cell B than to Cell C. Both of these mechanisms may be involved in the cell weight inequality. However, the present results indicate that they do not provide a complete explanation and that the wording of the causal question, the stimulus presentation format, and the distribution of individual differences in use of information across the four cells all play a part.

In several studies, the effects of the nature of judgment task on the use of contingency information have been investigated. For example, in a series of studies Waldmann (2000, 2001; Waldmann \& Holyoak, 1992) has compared causal, or predictive, and diagnostic reasoning tasks. These studies have been concerned with cue interaction effects - principally, blocking and overshadowing - in which manipulation of information about one cue affects judgments made of another cue. With designs of that sort, it is not possible to assess the contribution of each kind of contingency information. Given that use of the four cells varies depending on the wording of the causal question, it is likely that the use of the four cells would also differ between causal and diagnostic questions. In particular, the use of effect-absent information in diagnostic reasoning could be different from the use of cause-absent information in causal reasoning. Research comparing cell use in these two tasks could shed new light on the findings of that research.

In conclusion, the cell weight inequality should be viewed, to some extent, as a reflection of the forms of wording and stimulus presentation format that prevail in causal judgment studies. The consistency of the ordering of cell weights found in previous studies is, in part, a consequence of the consistency in the form of wording that has been used to express the causal question. Different forms of causal question result in different orderings of cell weights. Different stimulus presentation formats-in particular, formats that assign a clear role to cause-absent information - result in less idiosyncratic use of Cells C and D and greater weight, particularly to Cell D. If the meaning of a kind of information is made clear, people will use it for judgment.

\section{REFERENCES}

Allan, L. G. (1993). Human contingency judgments: Rule based or associative? Psychological Bulletin, 114, 435-448.

Anderson, J. R., \& Sheu, C.-F. (1995). Causal inferences as perceptual judgments. Memory \& Cognition, 23, 510-524.

Beyth-Marom, R. (1982). Perception of correlation reexamined. Memory \& Cognition, 10, 511-519.

Cheng, P. W. (1997). From covariation to causation: A causal power theory. Psychological Review, 104, 367-405.

Crocker, J. (1981). Judgment of covariation by social perceivers. Psychological Bulletin, 90, 272-292.

Crocker, J. (1982). Biased questions in judgment of covariation studies. Personality \& Social Psychology Bulletin, 8, 214-220.

HEIDER, F. (1958). The psychology of interpersonal relations. New York: Wiley.

Jenkins, H. M., \& WARD, W. C. (1965). Judgment of contingency between responses and outcomes. Psychological Monographs: General \& Applied, 79(1, Whole No. 594), 17.

KaO, S.-F., \& Wasserman, E. A. (1993). Assessment of an information integration account of contingency judgment with examination of subjective cell importance and method of information presentation. Journal of Experimental Psychology: Learning, Memory, \& Cognition, 19, 1363-1386. 
Keppel, G., Saufley, W. H., \& Tokunaga, H. (1992). Introduction to design and analysis: A student's handbook. New York: Freeman.

Levin, I. P., Wasserman, E. A., \& KaO, S. F. (1993). Multiple methods for examining biased information use in contingency judgments. Organizational Behavior \& Human Decision Processes, 55, 228-250.

MANDEL, D. R., \& LeHMAN, D. R. (1998). Integration of contingency information in judgments of cause, covariation, and probability. Journal of Experimental Psychology: General, 127, 269-285.

Matute, H., Arcediano, F., \& Miller, R. R. (1996). Test question modulates cue competition between causes and between effects. Journal of Experimental Psychology: Learning, Memory, \& Cognition, 22, 182-196.

McKenzIE, C. R. M. (1994). The accuracy of intuitive judgment strategies: Covariation assessment and Bayesian inference. Cognitive Psychology, 26, 209-239.

NisBett, R. E., \& Ross, L. (1980). Human inference: Strategies and shortcomings of social judgment. Englewood Cliffs, NJ: PrenticeHall.

Vallée-Tourangeau, F., Hollingsworth, L., \& Murphy, R. A. (1998). "Attentional bias" in correlation judgments? Smedslund (1963) revisited. Scandinavian Journal of Psychology, 39, 221-233.

WALDMANN, M. R. (2000). Competition among causes but not effects in predictive and diagnostic learning. Journal of Experimental Psychology: Learning, Memory, \& Cognition, 26, 53-76.

WaLdmann, M. R. (2001). Predictive versus diagnostic causal learning: Evidence from an overshadowing paradigm. Psychonomic Bulletin \& Review, 8, 600-608.

Waldmann, M. R., \& HolyoaK, K. J. (1992). Predictive and diagnostic learning within causal models: Asymmetries in cue competition. Journal of Experimental Psychology: General, 121, 222-236.
WARD, W. C., \& JENKINS, H. M. (1965). The display of information and the judgment of contingency. Canadian Journal of Psychology, 19, 231-241.

Wasserman, E. A., Dorner, W. W., \& Kao, S.-F. (1990). Contributions of specific cell information to judgments of interevent contingency. Journal of Experimental Psychology: Learning, Memory, \& Cognition, 16, 509-521.

Wasserman, E. A., Elek, S. M., Chatlosh, D. L., \& Baker, A. G. (1993). Rating causal relations: The role of probability in judgments of response-outcome contingency. Journal of Experimental Psychology: Learning, Memory, \& Cognition, 19, 174-188.

Wasserman, E. A., KaO, S.-F., Van Hamme, L. J., Katagiri, M., \& Young, M. E. (1996). Causation and association. In D. R. Shanks, K. J. Holyoak, \& D. L. Medin (Eds.), The psychology of learning and motivation: Vol. 34. Causal learning (pp. 207-264). San Diego: Academic Press.

White, P. A. (1984). A model of the layperson as pragmatist. Personality \& Social Psychology Bulletin, 10, 333-348.

White, P. A. (2000). Causal judgment from contingency information: Relation between subjective reports and individual tendencies in judgment. Memory \& Cognition, 28, 415-426.

$$
\text { 1. } R^{2}=\frac{\text { NOTE }}{\text { SS effect }+ \text { SS error }}
$$

This, despite the symbology, is not the square of a correlation coefficient. It measures the percentage of the total (relevant) variability that is associated with the variability of the treatment group or independent variable (Keppel et al., 1992).

APPENDIX A

Sample Patient Information Sheet, Experiment 1

\begin{tabular}{cll}
\hline \multicolumn{3}{c}{ Patient P.B. } \\
\hline Meal & Additive X & Blue Spots \\
\hline 1 & absent & yes \\
2 & absent & no \\
3 & absent & no \\
4 & absent & no \\
5 & present & yes \\
6 & absent & no \\
7 & absent & no \\
8 & present & no \\
9 & absent & yes \\
10 & absent & no \\
11 & present & yes \\
12 & present & no \\
13 & present & yes \\
14 & absent & yes \\
15 & present & no \\
16 & present & yes \\
17 & absent & no \\
18 & present & no \\
19 & absent & yes \\
20 & absent & no \\
& a &
\end{tabular}

To what extent does additive $\mathrm{X}$ cause an increase or decrease in the occurrence of blue spots in this patient after meals? 


\section{Experiment 1}

$\mathrm{A} \times \mathrm{C}: F(1,61)=7.08, M S_{\mathrm{e}}=418.74, p<.01$.

Means: $\mathrm{A} 4 \mathrm{C} 4=-7.49 ; \mathrm{A} 4 \mathrm{C} 8=-0.37 ; \mathrm{A} 8 \mathrm{C} 4=+2.21$; $\mathrm{A} 8 \mathrm{C} 8=+2.46$.

Wording $\times \mathrm{B} \times \mathrm{D}: F(1,61)=9.66, M S_{\mathrm{e}}=452.22, p<.01$.

Means for positive wording: B4D4 $=+3.67$; B4D8 $=+14.68$; B8D4 $=-4.24$; B8D8 $=-2.04$.

Means for negative wording: B4D4 $=+5.48$; B4D8 $=-14.77$; B8D4 $=+1.61$; B8D8 $=-10.79$.

Wording $\times \mathrm{A} \times \mathrm{C} \times \mathrm{D}: F(1,61)=8.64, M S_{\mathrm{e}}=550.69, p<.01$.

Means for positive wording: A4C4D4 = -6.65; A4C4D8 = +8.76; A4C8D4 = -13.97; A4C8D8 = -7.90; $\mathrm{A} 8 \mathrm{C} 4 \mathrm{D} 4=+19.10 ; \mathrm{A} 8 \mathrm{C} 4 \mathrm{D} 8=+16.69 ; \mathrm{A} 8 \mathrm{C} 8 \mathrm{D} 4=+0.37 ; \mathrm{A} 8 \mathrm{C} 8 \mathrm{D} 8=+7.73$.

Means for negative wording: A4C4D4 $=-6.80 ; \mathrm{A} 4 \mathrm{C} 4 \mathrm{D} 8=-25.27 ; \mathrm{A} 4 \mathrm{C} 8 \mathrm{D} 4=+15.81 ; \mathrm{A} 4 \mathrm{C} 8 \mathrm{D} 8=+4.56$; A8C4D4 = -6.70; A8C4D8 $=-20.27 ;$ A8C8D4 $=+11.87 ;$ A8C8D8 $=-10.14$.

\section{Experiment 2}

\section{Active-Wording Group}

$\mathrm{A} \times \mathrm{B} \times \mathrm{C}: F(1,38)=6.50, M S_{\mathrm{e}}=157.65, p<.05$.

Means: A6B3C3 = 52.09; $\mathrm{A} 6 \mathrm{~B} 3 \mathrm{C} 6=40.71 ; \mathrm{A} 6 \mathrm{~B} 6 \mathrm{C} 3=37.31 ; \mathrm{A} 6 \mathrm{~B} 6 \mathrm{C} 6=36.02 ; \mathrm{A} 12 \mathrm{~B} 3 \mathrm{C} 3=63.51$; $\mathrm{A} 12 \mathrm{~B} 3 \mathrm{C} 6=56.16 ; \mathrm{A} 12 \mathrm{~B} 6 \mathrm{C} 3=52.74 ; \mathrm{A} 12 \mathrm{~B} 6 \mathrm{C} 6=45.36$.

$\mathrm{A} \times \mathrm{B} \times \mathrm{D}: F(1,38)=7.21, M S_{\mathrm{e}}=233.33, p<.05$.

Means: A6B3D6 = 46.85; A6B3D12 = 45.95; A6B6D6 = 34.16; A6B6D12 = 39.17; A12B3D6 = 56.91; $\mathrm{A} 12 \mathrm{~B} 3 \mathrm{D} 12=62.77 ; \mathrm{A} 12 \mathrm{~B} 6 \mathrm{D} 6=49.65 ; \mathrm{A} 12 \mathrm{~B} 6 \mathrm{D} 12=48.45$.

$\mathrm{A} \times \mathrm{B} \times \mathrm{C} \times \mathrm{D}: F(1,38)=4.11, M S_{\mathrm{e}}=334.14, p<.05$.

Means: $\mathrm{A} 6 \mathrm{~B} 3 \mathrm{C} 3 \mathrm{D} 3=51.77 ; \mathrm{A} 6 \mathrm{~B} 3 \mathrm{C} 3 \mathrm{D} 12=52.40 ; \mathrm{A} 6 \mathrm{~B} 3 \mathrm{C} 6 \mathrm{D} 6=41.92 ; \mathrm{A} 6 \mathrm{~B} 3 \mathrm{C} 6 \mathrm{D} 12=39.50$; $\mathrm{A} 6 \mathrm{~B} 6 \mathrm{C} 3 \mathrm{D} 6=36.30 ; \mathrm{A} 6 \mathrm{~B} 6 \mathrm{C} 3 \mathrm{D} 12=38.32 ; \mathrm{A} 6 \mathrm{~B} 6 \mathrm{C} 6 \mathrm{D} 6=32.02 ; \mathrm{A} 6 \mathrm{~B} 6 \mathrm{C} 6 \mathrm{D} 12=40.02 ; \mathrm{A} 12 \mathrm{~B} 3 \mathrm{C} 3 \mathrm{D} 6=$ 63.57; A12B3C3D12 = 63.45; A12B3C6D6 = 50.25; $\mathrm{A} 12 \mathrm{~B} 3 \mathrm{C} 6 \mathrm{D} 12=62.10 ; \mathrm{A} 12 \mathrm{~B} 6 \mathrm{C} 3 \mathrm{D} 6=52.72$; $\mathrm{A} 12 \mathrm{~B} 6 \mathrm{C} 3 \mathrm{D} 12=52.75 ; \mathrm{A} 12 \mathrm{~B} 6 \mathrm{C} 6 \mathrm{D} 6=46.57$; $\mathrm{A} 12 \mathrm{~B} 6 \mathrm{C} 6 \mathrm{D} 12=44.15$.

\section{Experiment 2}

\section{Passive-Wording Group}

$\mathrm{A} \times \mathrm{C}: F(1,38)=5.82, M S_{\mathrm{e}}=170.99, p<.05$.

Means: A6C3 = 43.97; A6C6 = 39.81; A12C3 = 57.81; A12C6 = 48.66.

$\mathrm{B} \times \mathrm{C}: F(1,38)=4.47, M S_{\mathrm{e}}=297.04, p<.05$.

Means: B3C3 $=55.47 ;$ B3C6 $=45.93 ;$ B6C3 $=46.31 ;$ B6C6 $=42.53$.

\section{Experiment 3}

$\mathrm{B} \times \mathrm{C}: F(1,37)=9.36, M S_{\mathrm{e}}=609.45, p<.01$.

Means: B2C2 $=+58.53 ; \mathrm{B} 2 \mathrm{C} 6=+41.77 ; \mathrm{B} 6 \mathrm{C} 2=+39.70 ; \mathrm{B} 6 \mathrm{C} 6=+10.69$.

$\mathrm{C} \times \mathrm{D}: F(1,37)=13.74, M S_{\mathrm{e}}=479.79, p<.001$.

Means: C2D4 $=+43.61 ; \mathrm{C} 2 \mathrm{D} 12=+54.62 ; \mathrm{C} 6 \mathrm{D} 4=+14.14 ; \mathrm{C} 6 \mathrm{D} 12=+38.32$.

$\mathrm{B} \times \mathrm{C} \times \mathrm{D}: F(1,37)=15.00, M S_{\mathrm{e}}=371.26, p<.001$.

Means: B2C2D4 = +57.30; B2C2D12 $=+59.75$; B2C6D4 $=+27.91$; B2C6D12 $=+55.63$; B6C2D4 = $+29.91 ; \mathrm{B} 6 \mathrm{C} 2 \mathrm{D} 12=+49.49 ; \mathrm{B} 6 \mathrm{C} 6 \mathrm{D} 4=+0.37 ; \mathrm{B} 6 \mathrm{C} 6 \mathrm{D} 12=+21.01$. 